\title{
ESTUDO SOBRE A GEOGRAFIA NOS CURSOS DO PROEJA/IFES VITÓRIA - ES Fabiano Boscaglia ${ }^{1}$, Ligia ARANTES SAD ${ }^{2}$
}

\author{
Pós-graduação Lato Sensu em PROEJA, Instituto Federal do Espírito Santo \\ E-mail: fabianoboscaglia@yahoo.com.br, sadli@terra.com.br
}

\begin{abstract}
RESUMO
O presente artigo é resultado de uma pesquisa sobre o ensino de Geografia nos cursos técnicos do Programa Nacional de Integração da Educação Profissional com a Educação Básica na Modalidade de Educação de Jovens e Adultos (PROEJA) no Instituto Federal de Educação, Ciência e Tecnologia do Espírito Santo. O objetivo geral foi analisar o papel da geografia no currículo vigente dos cursos técnicos de Segurança do Trabalho, Edificações e Metalurgia e Materiais. Para isso, a escolha foi feita por uma pesquisa qualitativa, através da qual realizamos investigações bibliográficas, numa perspectiva da construção de um currículo integrado, dando ênfase ao PROEJA. Em seguida analisamos o currículo dos cursos técnicos e os documentos pedagógicos, como os planos de ensino. Juntamos a essas análises as observações das práticas de ensino dos professores e as respostas das questões dirigidas a estes, à equipe pedagógica e aos alunos. Dentre os resultados, identificamos que a organização curricular dos cursos técnicos de Segurança do Trabalho e Edificações favorece a integração e a motivação entre os professores de geografia para o trabalho interdisciplinar.
\end{abstract}

Palavras-chaves: Currículo, ensino de Geografia, integração.

\section{INICIANDO A CONVERSA}

Atualmente, um dos grandes desafios do ensino de Geografia, reside na tentativa de integrar os conteúdos e conceitos da disciplina à realidade dos alunos, assim como sua integração com outras disciplinas, possibilitando a compreensão das transformações socioespaciais ocorridas no espaço geográfico no qual estão inseridos. De fato, percebe-se que as práticas de ensino pouco contemplam o entendimento, a reflexão, a críticidade muito menos a perspectiva de que todo aluno é sujeito ativo de seu processo de formação e de desenvolvimento intelectual, afetivo e social (CAVALCANTI, 2007, p.66).

Em termos da organização curricular em nossas escolas - as quais estabelecem um plano pedagógico "de transmissão de conhecimentos e de inclusão de valores socialmente aceitos" (DAVINI, 1991, p. 282) - ainda impera a fragmentação do conhecimento. As disciplinas do currículo são organizadas de forma isolada e professores e alunos devem dar conta de todos os conteúdos, independentemente das características próprias de cada turma ou de seu desenvolvimento anterior.

$\mathrm{Na}$ Educação de Jovens e Adultos (EJA), à medida que o aluno adulto traz consigo uma gama de conhecimentos adquiridos no cotidiano, seja, no trabalho, na escola, na comunidade ou em outros espaços de vivência, as práticas de ensino devem valorizar essa diversidade de conhecimentos e significados, atuando de forma integrada com as várias disciplinas curriculares.

Diante desse contexto, o foco de nossa investigação esteve centrado na problemática do ensino de Geografia, desenvolvido nos cursos do PROEJA, na perspectiva de examinar e responder à seguinte questão: Como está a se constituir a integração entre a Geografia e as outras disciplinas de formação geral, como também entre as de formação técnica?

Nesse sentido, o trabalho de campo da pesquisa direcionou-se para o Instituto Federal de Educação, Ciência e Tecnologia do Espírito Santo (Ifes) no campus Vitória, especificamente nos cursos Técnico de Segurança do Trabalho, Técnico em Edificações e Técnico em Metalurgia e Materiais do PROEJA, com objetivo geral de analisar o papel da geografia no currículo vigente. De modo mais específico, com a preocupação de identificar quais são os conteúdos e como são trabalhados para que possa viabilizar uma integração da Geografia com outras disciplinas da formação básica e profissional, bem como as ações de interdisciplinaridade

\footnotetext{
${ }^{1}$ Fabiano Boscaglia é Geógrafo e Especialista em PROEJA, professor da Secretaria de Estado da Educação, SEDU-ES.. ${ }_{2}$ Ligia Arantes Sad é Professora do Programa de Pós-Graduação em Educação - UFES e da Especialização PROEJA - Ifes.
} 
entre as disciplinas e as possíveis práticas que possam contribuir para a formação crítica dos sujeitos em sua profissionalização.

Para tal, optamos por uma pesquisa qualitativa, através da qual realizamos investigações bibliográficas e de fundamentos teóricos sobre o PROEJA e as possíveis indicações de currículo para essa modalidade, indicando o papel da Geografia como possibilidade de formação crítica cidadã. Também buscamos analisar os documentos pedagógicos - PPP's, planos anuais de ensino, Proposta Metodológica da disciplina de Geografia, observações em sala de aula e questionários, coletados in locus da pesquisa, a fim de refletir sobre o ensino de Geografia e suas perspectivas de integração com as disciplinas de formação geral e específica nos cursos do PROEJA do campus Vitória.

\section{PROEJA: CURRÍCULO E ENSINO DE GEOGRAFIA}

O PROEJA teve origem a partir do decreto 5.478 de 24/06/2005 e expôs a decisão governamental de atender à demanda de jovens e adultos pela oferta de educação profissional técnica de nível médio, da qual, em geral, são excluídos, bem como, em muitas situações, do próprio ensino médio e fundamental. Nessa direção o objetivo do programa é de promover a integração entre a educação básica e a profissional na modalidade EJA e romper com esta dualidade entre formação geral e específica. Também o que se pretende com o programa é "uma integração epistemológica, de conteúdos, de metodologias e de práticas educativas, integrando teoria e prática e saber e saber-fazer" (BRASIL, 2007).

Este programa implantado nos Institutos Federais de Educação, Ciência e Tecnologia de modo mais específico visa promover a integração dos conhecimentos gerais e técnicos, por meio de práticas de ensino integradas numa abordagem de conteúdos inter e transdisciplinares. Nessa perspectiva as práticas integradoras consistem em metodologias dinâmicas que possibilitam a formação do sujeito por meio da integração de disciplinas de formação geral e especificas que compõem a grade curricular dos cursos. Assim procuramos analisar algumas posições teóricas sobre o conceito de currículo e seus tipos, que convergem para essa perspectiva de integração proposta pelo PROEJA.

Para Sacristán (2006, p. 15),

o currículo supõe a concretização dos fins sociais e culturais, de socialização, que se atribui à educação escolarizada, ou de ajuda ao desenvolvimento, de estímulos e cenários, reflexo de um modelo educativo determinado pela comunidade escolar.

Para o autor, o currículo é algo que adquire forma e significado educativo e está em constante transformação no decorrer das práticas desenvolvidas na escola.

Nesse sentido, o currículo pode ser compreendido como um projeto simbiótico que integra a sociedade-cultura-prática, e permite um diálogo entre os agentes sociais. Esta concepção de currículo como uma construção social se aproxima dos delineamentos curriculares propostos pelo Documento Base do PROEJA, pois enfatiza que o currículo antes de ser uma proposta pré-definida, deve-se orientar pelo diálogo constante com a realidade. Para o documento

o currículo é um desenho pedagógico que corresponde a organização da instituição à qual articula dinamicamente experiências, trabalho, valores, ensino, prática, teoria, comunidade, concepções de saberes observando as características históricas, econômicas e socioculturais do meio em que o processo se desenvolve (BRASIL, 2007, p. 49).

Ainda nessa perspectiva de entender as concepções de currículo a fim de compreender como se dão as práticas de ensino integradas, Davini (1991, p. 282) considera que o currículo "é um plano pedagógico e institucional para orientar a aprendizagem dos alunos de forma sistemática", observando uma ampla definição das concepções de aprendizagem e práticas que orientam o currículo.

Desse modo, a autora considera que o currículo do tipo integrado é uma opção educativa que permite:

uma efetiva integração entre ensino e prática profissional; a real integração entre prática e teoria e o imediato teste da prática; um avanço na construção de teorias a partir do anterior; a integração ensino - trabalho-comunidade, implicando uma imediata contribuição para esta última; e adaptação a cada realidade local e aos padrões culturais próprios de uma determinada estrutura social (DAVINI, 1991, p. 284). 
Desta forma, o currículo integrado contribui para superar as dificuldades impostas por modelos curriculares tradicionais, disciplinares e rígidos, possibilitando a valorização da realidade do educando numa abordagem contextualizada dos conteúdos e práticas inter e transdisciplinares, com metodologias dinâmicas que consideram os saberes adquiridos em espaços de educação não formal. Essa concepção de currículo se aproxima das propostas do PROEJA para o ensino integrado.

A integração de conhecimentos, segundo Ramos (2005, p. 24), seja entre a formação geral ou especifica, ou ainda, por exemplo no foco deste trabalho - entre a Geografia e outras disciplinas - é o grande desafio da integração educação básica e profissional. Para ela, a educação integrada, interdisciplinar, deve estabelecer uma visão holística da realidade, sendo mediada a partir do currículo que exigirá uma relação entre os conhecimentos gerais e específicos por meio das seguintes ações:

problematizar fenômenos; explicitar teorias e conceitos fundamentais, identificando suas relações no campo da disciplina e com outras; situar os conceitos tendo como referência sua apropriação tecnológica, social e cultural; estabelecer múltiplas relações na organização dos componentes curriculares e as práticas pedagógicas (RAMOS, 2005, p. 21).

Nesse sentido, os currículos e, principalmente, as práticas de ensino que constituem a materialização dos currículos em sala de aula devem promover a problematização de fenômenos, temas e situações do cotidiano dos alunos, buscando a significação e aplicação dos conceitos e teorias das disciplinas de formação geral e especifica à sua realidade profissional e cultural. Explicitar as teorias e conceitos é fundamental na compreensão do(s) tema(s)/objeto(s) estudado(s) de maneira que os alunos possam identificar e localizar os respectivos campos de conhecimento, sejam áreas, disciplinas gerais ou técnicas, identificando assim suas relações interdisciplinares que levam a compreensão holística da realidade.

$\mathrm{Na}$ Educação de Jovens e Adultos é preciso fugir de práticas que tornem o aluno um receptor em que o professor deposita os conhecimentos. Além disso, é preciso afastar-se da consciência bancária da educação que impede o ato de criar e recriar, de significar e ressignificar (FREIRE, 1979). Não cabe ao nosso jovem e adulto uma visão ingênua sobre o contexto em que vive, mas sim uma conscientização crítica que possibilite o exercício de sua cidadania no espaço socioeconômico, político e cultural no qual se insere.

$\mathrm{Na}$ Geografia é crescente o movimento que busca superar a função descritiva e enumerativa desenvolvida até finais da década de 1970 do século passado, intitulada Geografia Tradicional. Para Suzuki (2009, p. 234) a Geografia, com o saber que tem na relação estabelecida entre a natureza e a sociedade, deve desenvolver práticas de ensino que superem a memorização e identificação como formas únicas de saber. Essa abordagem analítica e integradora entre natureza e sociedade ressalta a possibilidade de aproximar o educando da realidade na qual está inserido, permitindo-Ihe desvendar e criar a partir de seu cotidiano.

Nessa perspectiva de pensar sobre o papel das práticas de ensino de Geografia numa visão socioconstrutivista, concordamos com Cavalcanti (2007, p.67) ao considerar que

elas devem motivar o aluno a ser o sujeito ativo de seu processo de formação e de desenvolvimento intelectual, afetivo e social. Cabe ao professor ser o mediador do encontro ou confronto do sujeito com o conhecimento, ou seja, do aluno com o conteúdo escolar.

Em grande medida, esta concepção sobre o desenvolvimento das práticas de ensino de geografia se alinha com os objetivos da formação integrada pelo eixo trabalho-ciência e cultura proposta pelo PROEJA. Essa mesma autora ressalta que o professor deve desenvolver atividades em sala de aula que considerem a escola um espaço de significados, cultura, como também de encontro de culturas.

Esta é uma tarefa das mais relevantes no ensino de Geografia e, ao mesmo tempo, uma das mais difíceis de fazer, ou seja, propiciar que aluno construa significados do conteúdo estudado. Na EJA ou no PROEJA é papel da geografia contribuir para o desenvolvimento de um modo de pensar sobre o mundo e as realidades que o cercam. "Para tanto, não basta apenas apresentar o conteúdo, é preciso trabalhar esses conteúdos realizando um tratamento didático para que se transformem em ferramentas simbólicas do pensamento"(CAVALCANTI, 2007, p. 72).

\section{A GEOGRAFIA NOS CURSOS TÉCNICOS DO PROEJA/IFES - VITÓRIA}

Como já mencionamos nosso locus de pesquisa foi o Ifes Vitória, especificamente, nos cursos técnicos em Segurança Trabalho, Metalurgia e Materiais e Edificações na modalidade PROEJA. Após a investigação bibliográfica e discussão sobre o assunto, iniciamos o levantamento de dados para atender aos objetivos da pesquisa. Inicialmente fizemos contato com a coordenação dos cursos afim de solicitar à equipe pedagógica os 
seguintes documentos: Projeto Político Pedagógico (PPP) dos cursos técnicos, os planos anuais de ensino da disciplina de Geografia e projetos interdisciplinares e/ou integradores, uma vez que estes documentos expressam o caminho pedagógico e metodológico do currículo, sendo uma fonte importante para identificarmos práticas de ensino que possibilitem a integração.

Em seguida solicitamos aos professores de Geografia, por intermédio da coordenação do PROEJA, autorização para realizar observações em suas aulas no período de Outubro/2009 a Agosto/2010. Essas observações foram fundamentais para visualizarmos aspectos da prática dos currículos integrados propostos para os cursos em estudo.

No intuito de desenvolver estas observações, buscamos em nossa base teórica critérios apontados por Ramos (2007) para um currículo integrado e elaboramos um instrumento contendo critérios que possibilitaram perceber se a aula perfazia o caminho da integração entre as disciplinas tanto de formação geral como técnica, bem como com a realidade social do aluno. Além disso, no semestre 2010/1 aplicamos questões para alunos, professores e equipe pedagógica na intenção de que relatassem suas visões sobre a questão da integração da Geografia com outras disciplinas de formação geral e específica nos cursos técnicos estudados.

De posse dos documentos pedagógicos solicitados, das observações e das respostas dos questionários, iniciamos a análise tecendo uma discussão e reflexão a respeito da organização curricular na perspectiva de integração da Geografia e demais disciplinas de formação geral e técnica nos cursos do PROEJA/Ifes - Vitória. Realizamos essa discussão, considerando três aspectos: conteúdos, metodologias e práticas de Geografia nos cursos técnicos.

$\mathrm{Na}$ análise dos $P P P^{\prime}$ 's, buscamos verificar como a Geografia está organizada nas grades curriculares dos três cursos técnicos integrados: Segurança do Trabalho, Edificações e Metalurgia e Materiais. Ao mesmo tempo, buscamos conferir se há possibilidade de integração dessa disciplina com as demais de formação geral e específica, visto que concordamos com a ideia de a organização curricular sustentar a ação pedagógica, pois ela concretiza os esquemas teóricos e práticos, bem como as tarefas acadêmicas desenvolvidas pelos professores (SACRISTÁN, 2006, p.105).

Na grade curricular do curso Técnico Integrado de Segurança do Trabalho a disciplina de Geografia está presente no 1으 2을 e 3o módulos. Ela encontra-se distribuída entre as disciplinas de formação geral e especificas, tendo 36 horas de carga horária semestral e 108 horas no total dos três períodos, com três aulas por semana em cada um desses módulos.

No primeiro módulo, na disciplina de Geografia poder-se-iam desenvolver atividades integradas ${ }^{3}$ com as disciplinas de Matemática, Língua Portuguesa, História, Filosofia e Artes, que compreendem o grupo de formação geral neste módulo, mais a Informática Básica do núcleo diversificado e, ainda, com Fundamentos da Segurança do Trabalho da área específica. Se as atividades pedagógicas integradoras fossem desenvolvidas por áreas de conhecimento, a Geografia - pertencente às Ciências Humanas - encontraria pelo menos a História e a Filosofia para o diálogo interdisciplinar, como um passo para a integração.

No segundo módulo, o grupo de formação geral é formado pelas disciplinas de Matemática, Língua Portuguesa, História, Sociologia, Física e Biologia, que poderiam dialogar com a Geografia, e mais duas disciplinas de formação específica - Informática Aplicada e Processos Industriais. Na perspectiva de integração por área de conhecimento (grupo de ciências humanas) sairia a Filosofia e entraria a Sociologia, continuando junto com História.

No terceiro módulo, último em que a Geografia aparece na grade curricular do curso, o grupo de formação geral é formado pelas disciplinas de Matemática, Língua Portuguesa, História, Física, Filosofia e Biologia que, juntas com a Geografia, buscariam integrar-se com as específicas - Direito Aplicado e Técnicas de Didática e Pesquisa. Neste módulo a área de Ciências Humanas tem as disciplinas de História, Filosofia e Geografia.

Nesse documento do curso Técnico Integrado de Segurança do Trabalho há uma oportunidade de articulação entre as disciplinas de formação geral e técnica que, por ações dos envolvidos no processo educativo, pode ser o passo inicial em direção a um currículo mais integrado. Concordamos que entre as características do currículo integrado há a necessidade de permitir "uma efetiva integração entre ensino e prática profissional; a real integração entre prática e teoria (...)" (DAVINI,1991, p. 284), que, no caso desse curso, estaria oportunizando um início de integração com essa articulação.

O curso de Metalurgia e Materiais possui organização curricular semelhante ao de Segurança do Trabalho, pois a disciplina de Geografia é cursada em três dos oito módulos do curso, tendo carga horária semestral de 36 horas e 108 no total. A disciplina possui três aulas por semana no 1ㅇ, 2o e 4ㅇ módulos. Entretanto, as semelhanças se restringem apenas à organização por módulos, pois a proposta de integração

\footnotetext{
${ }^{3}$ No sentido em que uma mesma atividade possibilitaria a articulação de conteúdos entre as disciplinas de formação geral e específica.
} 
indicada para os cursos do PROEJA, em que as disciplinas de formação geral devem integrar-se às de formação técnicas por meio das práticas, não se apresentam na organização curricular do curso. Ou seja, as disciplinas de formação geral, incluindo a Geografia, são ministradas até o quarto módulo, e depois o currículo desses cursos somente consta das disciplinas específicas a essa área profissional. Dessa maneira, a Geografia pode se relacionar na ação didática apenas com o grupo de formação geral e com as disciplinas do núcleo diversificado, no caso: Qualidade de vida (1 módulo), Metodologia (2 módulo) e Informática (4 módulo).

Por outro lado, o curso de Edificações possui uma organização em regime anual no qual a Geografia é ofertada no 1 o ano do curso, tendo carga horária total de 81 horas, com três aulas semanais. Neste período de oferta da disciplina, a organização curricular possui, além da Geografia, cinco disciplinas de formação geral (Língua Portuguesa, Matemática, Física, História e Artes), uma do núcleo diversificado (Projeto integrador) e duas do grupo de formação específica (Desenho técnico e Construção Civil I). Nesse sentido, a organização curricular do curso possibilita, mas não garante que entre as disciplinas gerais e técnicas haja diálogo e articulações, a construção de uma integração. Cabe às práticas de ensino, por meio das ações pedagógicas dos professores e alunos, o importante papel de articular os conteúdos e promover a integração dos conhecimentos entre as disciplinas.

Diante da organização curricular desses três cursos técnicos integrados, podemos refletir sobre duas situações que nos ajudaram a melhor compreender e problematizar a questão investigada por este trabalho. A primeira é que nos cursos de Segurança do Trabalho e Edificações há uma ruptura com modelos curriculares tradicionais, no que diz respeito à dicotomia entre formação geral e técnica, pois desde o início do curso são ministradas concomitantemente disciplinas de formação geral e de formação técnica. Portanto, a organização curricular e metodológica desses dois cursos cria a possibilidade de diálogo entre as disciplinas desde o 10 módulo ou ano, contribuindo dessa forma para que os professores tenham condições de construir práticas de ensino contextualizadas com a realidade técnica profissional do educando, no entanto não sabemos se isso efetivamente está ocorrendo.

Em contraste, temos a segunda situação, na qual o curso de Metalurgia e Materiais ainda permanece em um modelo tradicional de organização curricular da educação técnica de nível médio, visto que a formação geral é feita nos dois primeiros anos do curso. Neles as disciplinas de formação geral não têm contato com as disciplinas técnicas, e as específicas são ministradas nos outros dois anos finais da formação. Neste modelo as disciplinas não contemplam as indicações características para uma formação integrada do aluno, estabelecendo a relação que deve ser indissociável entre trabalho, ciência e cultura, prevista nas diretrizes do PROEJA. Além disso, as possibilidades de desenvolver práticas de ensino integradas ficam praticamente inviáveis, uma vez que tanto as disciplinas e os conteúdos da Proposta Metodológica são apresentados sem aparente conexão quanto os professores não têm encontros sistematizados para planejar atividades interdisciplinares.

Com estas considerações sobre a organização curricular dos cursos técnicos, especificamente nos cursos de Segurança do Trabalho e Edificações em que a proposta curricular abre a possibilidade de integração, buscamos analisar os conteúdos e metodologias propostos pela geografia, examinando os planos anuais de ensino da disciplina de Geografia, denominados Proposta Metodológica de Geografia, afim de observar as possíveis ações que envolvem os conteúdos selecionados e as práticas de ensino, mesmo que não sejam explicitamente orientadas pela Proposta. Para isso, as observações da prática em sala de aula poderiam contribuir nos auxiliando a verificar as práticas de integração dos conhecimentos gerais e específicos nestes cursos técnicos. No entanto, como as observações foram restritas, por motivos alheios à nossa vontade, vamos aliá-las com os demais dados para que possam subsidiar as análises e indicações resultantes desse trabalho de investigação. Adicionamos e essa discussão as duas observações feitas em sala de aula dos primeiros módulos do curso técnico de Segurança do Trabalho.

A Proposta Metodológica de Geografia se resume em um esquema de temas/ conteúdos praticamente iguais para todos os cursos, definida em módulos ou trimestres. Os temas/conteúdos foram organizados em três eixos: Meio Ambiente para o primeiro módulo com os conteúdos: aspectos físicos - relevo, clima, vegetação, hidrografia, problemas ambientais e energia; No segundo módulo o eixo Modelo Econômico com os seguintes assuntos: industrialização, população, urbanização e agricultura. E no terceiro eixo, a Geopolítica, com os conteúdos que tratam da nova ordem mundial, blocos econômicos, comércio exterior e migrações internacionais.

Na Proposta Metodológica de Geografia foram descritos os conteúdos, mas os objetivos e as metodologias não foram mencionados, dificultando saber como os conteúdos seriam desenvolvidos em sala de aula. Da forma em que estão organizados os conteúdos, pode-se considerar que as práticas têm orientação baseadas no ensino tradicional, no sentido de que a ação didática conduzida pelo professor proporciona um ensino fundamentado na mera exposição dos conteúdos ali listados. Isto na Geografia configura-se quando o 
professor menciona algum fenômeno social, cultural, político ou natural e apenas o descreve e explica, de forma descontextualizada do lugar ou espaço que cercam o aluno.

Além dessa possível prática, quando analisamos alguns conteúdos de Geografia elencados na proposta, observou-se uma sequência de assuntos que poderiam implicar numa abordagem fragmentada, que frequentemente ocorre no interior da própria disciplina, a separação dos assuntos em Geografia Física e Geografia Humana. Por exemplo, no primeiro módulo ou trimestre, o tema Meio Ambiente representaria a Geografia Física em que o aluno estudaria os aspectos físicos como o relevo, o clima, o solo, a vegetação, a hidrografia, etc., sem envolver uma visão holística do papel da sociedade sobre essas bases físicas da superfície terrestre.

Muitas vezes esses conteúdos são desenvolvidos de forma desconectada e desarticulada da realidade, e neste caso essa ação não é significativa para a formação geral do aluno e muito menos sua formação técnica. O mesmo poderia acontecer no segundo e terceiro módulo ou trimestre, no qual os assuntos estariam relacionados aos sistemas produtivos e políticos configurando o campo da Geografia Humana, prevalecendo uma descrição das atividades humanas sem levar em consideração as dinâmicas integradas entre as relações sociais com o meio ambiente formado por bases naturais. Uma ressalva precisa ser feita a respeito da proposta explicitada, pois não impede que um professor mais experiente na modalidade PROEJA, e preocupado com uma integração curricular, possa implementar aulas que permitam o diálogo entre esses conteúdos listados.

Como esclarece Santos (2008, p. 98), não há geografia física que não seja uma parte da geografia humana, pois o homem é o sujeito que atua sobre a natureza, sendo o planeta Terra o objeto em que o ser humano usa suas forças intelectuais e físicas sobre um conjunto de elementos naturais (geografia física) indispensáveis para se manter em grupo. Portanto, a Geografia escolar deve assumir uma proposta de ensino que possibilite o aluno uma visão integrada do saber geográfico proporcionando-o entender as relações sociais que constitui o espaço geográfico, bem como sua inserção nesse espaço em escala local, regional e global.

Nas fichas feitas para observações da sala de aula das professoras de Geografia, com base nos critérios definidos no instrumento de observação, e ainda buscando examinar como estão a se constituir as práticas de ensino de Geografia integradas com as demais disciplinas, damos destaque a três critérios: se a professora problematiza os conteúdos ou fenômenos estudados relacionando-os à formação técnica; se explicita teorias e conceitos fundamentais do conteúdo da disciplina, identificando suas relações com outras disciplinas; e se utiliza práticas pedagógicas significativas, que propiciam a participação do aluno na produção do conhecimento.

Na primeira aula observada do curso de Segurança do Trabalho, notamos que os conteúdos foram trabalhados a partir de uma prática pedagógica tradicional bem conhecida pelos professores: listas de exercícios de fixação. Os conteúdos propostos nos exercícios aprofundaram os conhecimentos no âmbito da formação geral, pois, explicitavam teorias e conceitos da Geografia, bem como de outras disciplinas de formação geral. Entretanto, não houve por parte da professora, em nenhum momento, a tentativa de promover uma discussão que chamasse atenção sobre estes relacionamentos com as outras disciplinas de formação geral e, tampouco, com as de formação profissional.

Na segunda aula observada aconteceram algumas mudanças, em especial na prática pedagógica articulada pela professora. A aula anterior, que preconizava uma prática em estilo tradicional, apresentou-se diferenciada nesta segunda observação, com uma organização dinâmica entre os alunos, os quais dispostos em círculo, promoveram um debate sobre os conteúdos propostos para o encontro. A professora, utilizando-se de questões elaboradas previamente, mediou a discussão em sala de aula, envolvendo participação dialogada dos alunos, com objetivo de que estes fossem capazes de elaborar uma rápida síntese dos conteúdos estudados. Ressaltamos que mais uma vez não houve articulação entre os conteúdos de Geografia com os conhecimentos técnicos da formação profissional.

Nesses dois momentos em que estivemos presentes na sala de aula do PROEJA, embora poucos, foi possível observar e refletir sobre a complexidade e as dificuldades de se construírem práticas de ensino significativas, entendendo as necessidades do educando, jovem e adulto, seguindo as diretrizes do PROEJA. Desenvolver os conteúdos propostos pela disciplina não nos pareceu ser o grande desafio da professora, mas, sim, integrar esses assuntos numa abordagem que estabelecesse múltiplas relações com a realidade do aluno, bem como destacando sua apropriação social, cultural e tecnológica. Este certamente é um percurso desafiante para as práticas de ensino não só de Geografia, como também das demais disciplinas gerais e técnicas.

Não obstante, Cavalcanti (2007, p. 71), ressalta que a tarefa de ensinar a geografia é possibilitar que os conteúdos sejam objetos de conhecimento para os alunos, e assim as práticas de ensino devem possibilitar que ao aluno atribua significados articulados aos conhecimentos da sua formação humana e profissional, cabendo aos professores a mediação desse processo. 
Tendo apontado essas dificuldades, seja pela organização curricular, pelos conteúdos e metodologias, bem como pelas práticas de ensino, que no âmbito da Geografia estão longe de atender a finalidade de integração, buscamos por meio de questões dirigidas aos professores, a equipe pedagógica e aos alunos uma amostra de seus discursos sobre a integração da Geografia com as disciplinas de formação geral e específica.

Aos professores de Geografia e outros das disciplinas técnicas, a questão foi: Quais os desafios da integração da Geografia com as outras de disciplinas de formação geral e técnica, bem como as específicas com Geografia? Desse questionamento destacamos a obtenção das seguintes respostas:

- "Um dos principais problemas ou desafios da integração se refere à questão metodológica, pois temos alunos que se encontram em tempos diferentes de aprendizagem, e isto dificulta a articulação entre as disciplinas";

- "Espaços ocasionais de encontro entre as disciplinas, não garantindo a continuidade curricular e muito menos metodológica";

- "Promover o trabalho interdisciplinar";

- "Desenvolver práticas de ensino que possibilitem o diálogo entre os conteúdos de formação geral e especifica";

- Professores que insistem na ideia de separação entre a formação geral e técnica, dizendo que não há nenhuma ligação da sua disciplina com a Geografia";

Para a equipe pedagógica foi lançada a seguinte questão: Quais os desafios na integração das disciplinas de formação geral e específica e como a Geografia tem contribuído para essa integração? Recebemos as seguintes respostas

- "Romper com a organização de tempos e espaços na instituição, no qual áreas de formação são separadas por coordenadorias, que na maioria das vezes não se comunicam";

- "O planejamento coletivo ainda é pouco frequentado pelos professores, principalmente pelos docentes da área técnica";

- "A disciplina de Geografia é privilegiada pelo seu abrangente campo de estudo, o que facilitaria a discussão de temáticas entre as diversas disciplinas, entretanto isso não é desenvolvido";

Aos alunos perguntamos se eles têm percebido algum aspecto que demonstre a integração entre a Geografia e as outras disciplinas de formação geral e técnica e solicitamos que justificassem com exemplos. Obtivemos as seguintes respostas:

- Três alunos responderam que não há nenhuma integração, e justificaram dizendo:

_ "As disciplinas se fundamentam em livros de normas regulamentadoras, onde são raras as vezes que precisamos utilizar os conhecimentos da Geografia".

- "Ficamos o módulo todo estudando 1a e 2a Guerra Mundial, sem nenhuma integração; se tivesse estudado a Geografia do Brasil seria mais útil ao seu curso".

_ "Na matéria de Geografia do PROEJA não temos nenhuma referência ou ligação com o técnico, (...) como somos da área de metalurgia em que acabamos por mexer com materiais pesados, acho que algo voltado para ecologia, natureza, meio ambiente, seria muito proveitoso".

- Dois alunos responderam que têm percebido a integração, justificando:

_ “(...) as matérias de Topografia e Mecânica dos Solos aplicam em seus conteúdos fundamentos de Geografia como localização e coordenadas geográficas".

_ "A professora que dava aula na minha turma sempre relacionou as aulas com alguma coisa do curso".

- E 1 (um) aluno concorda que houve integração somente entre as disciplinas da formação geral;

Estes relatos nos mostram que o caminho da integração ainda é algo que começa a ser trilhado pela Geografia e demais disciplinas de formação geral e específica. A nosso ver, mais efetivo do que demonstrar nos documentos possibilidades das disciplinas interagirem é colocar isto em prática. Para tanto, faz-se necessário que a escola, de modo mais amplo, assuma tal compromisso. Especificamente, os professores que são os mediadores e facilitadores das ações pedagógicas integradas precisam reivindicar e utilizar espaços de discussões e reflexões comuns para direcionamentos e planejamentos, de modo a conduzir a efetividade dessas ações. 


\section{CONSIDERAÇÕES FINAIS}

Diante das análises feitas sobre a presença da Geografia na organização curricular dos cursos técnicos integrados do PROEJA, da Proposta Metodológica de Geografia que define os conteúdos para cursos, das observações feitas em sala de aula sobre as práticas de ensino desenvolvidas e dos relatos de professores, equipe pedagógica e alunos sobre as dificuldades e desafios de promover metodologias integradoras, podemos considerar que existem possibilidades, ou caminhos abertos para se constituir práticas de ensino integradas, envolvendo a Geografia e demais disciplinas de formação geral e técnica, pois:

- A organização curricular dos cursos técnicos, especificamente os de Segurança do Trabalho e Edificação, estão estruturados de maneira que as disciplina de formação geral e específicas possam dialogar desde o 1응́dulo ou ano de curso, dessa forma favorecendo a integração;

- $\quad$ Existe a participação dos professores de Geografia no grupo de formação e de elaboração dos Projetos Políticos Pedagógicos dos cursos, bem como espaço em comissões para a elaboração de material didático que melhor atenda as especificidades do PROEJA;

- Há motivação, pré-disposição entre os professores de Geografia para o trabalho numa perspectiva interdisciplinar;

- A Proposta Metodológica de Geografia para os cursos técnicos reformulada com definições mais detalhadas dos conteúdos e metodologias pode viabilizar o diálogo entre a Geografia e as demais disciplinas no caminho da integração.

Entendemos, portanto, que ao finalizar este estudo investigativo, não tecemos propriamente conclusões, mas elaboramos algumas considerações pertinentes as nossas análises dos documentos e dados respondendo aos objetivos traçados, deixando reflexões e outras questões em aberto, indicando a necessidade de continuação das pesquisas no longo caminho a percorrer e avançar na direção da construção coletiva de um currículo integrado que abranja o PROEJA.

\section{REFERÊNCIAS}

BRASIL. Geografia na Educação de Jovens e Adultos. Brasília. Ministério da Educação, Secretaria de educação básica, 2006b. Disponível em: <http://portal.mec.gov.br/seb/arquivos/pdf/Geografiaparte1de6.pdf>. Acesso em: 14 jun. 2009.

BRASIL. Programa nacional de integração da educação profissional com a educação básica na modalidade de educação de jovens e adultos. Secretaria de educação profissional e tecnológica. Brasília. 2007. Disponível em: <http://portal.mec.gov.br/setec/arquivos/pdf2/proeja medio ok.pdf>. Acesso em: 14 jun. 2009.

CAVALCANTI, Lana de Souza. Ensino de geografia e diversidade: construção de conhecimentos geográficos escolares e atribuição de significados pelos diversos sujeitos do processo de ensino. In. CASTELLAR, Sonia. Educação geográfica: teorias e práticas docentes. 2a ed., São Paulo: Contexto, 2007. (Novas abordagens. GEOUSP; v. 5)

DAVINI, M.C. Currículo integrado. In: SANTANA, J.P., CASTRO, J.L. Capacitação em desenvolvimento de recursos humanos de saúde. Natal: EDUFRN, 1991, p. 281-289.

FREIRE, Paulo. Educação e mudança. Ed. Paz e Terra - Rio de Janeiro: 1979.

GIL, Antonio Carlos. Métodos e Técnicas de Pesquisa Social. São Paulo: Atlas, 1999.

INSTITUTO FEDERAL DO ESPIRITO SANTO (Brasil). Projeto Político-Pedagógico do Curso Técnico em Segurança do Trabalho Integrado ao Ensino Médio na Modalidade Proeja. 2009. Vitória.

(Brasil). Projeto de Curso Técnico em Edificações Integrado com o Ensino Médio PROEJA. 2010. Vitória.

(Brasil). Projeto de ensino médio para jovens e adultos trabalhadores - EMJAT. 2009. Vitória.

RAMOS, M. Possibilidades e desafios na organização do currículo integrado. In: (Orgs.) Ensino médio integrado: concepções e contradições. São Paulo: Cortez, 2005. p. 106 - 127.

FRIGOTTO, G; CIAVATTA, M.

SACRISTÁN, J. Gimeno. 0 currículo - uma reflexão sobre a prática. Ed. Artimed. 3ạ edição, reimpressão 2006. Porto Alegre. 